\title{
Hemiarthroplasty in Complex Proximal Humeral Fractures Is uncemented methaphyseal corundum blasted titanium humeral stem an efficent alternative?
}

\begin{abstract}
ANDREI SCRIPCARU ${ }^{1}$, GRIGORE BEREA ${ }^{2}$, ELENA CARMEN COTRUTZ ${ }^{3 *}$, CRISTINEL IONEL STAN ${ }^{4 *}$, BOGDAN PUHA ${ }^{1}$
${ }^{1}$ Grigore T. Popa University of Medicine and Pharmacy, Faculty of Medicine, Department of Orthopedics and Traumatology, Surgical Sciences (II), 16 Universitatii Str., 700115, lasi, Romania

${ }^{2}$ Emergency County Hospital Piatra Neamt, Department of Orthopaedics and Traumatology, 1 Traian Blvd., 611003, Piatra Neamt, Romania

${ }^{3}$ Grigore T. Popa University of Medicine and Pharmacy, Faculty of Medicine, Department of Morphofunctional, Sciences (II), 16 Universitatii Str., 700115, Iasi, Romania

${ }^{4}$ Grigore T. Popa University of Medicine and Pharmacy, Faculty of Medicine, Department of Morphofunctional Science (I), Discipline of Anatomy, 16 Universitatii Str., 700115, lasi, Romania

The aim of this experimental studyis to reveal the design and characteristics of unipolar shoulder prosthesis type Arrow (Groupe $F H \otimes$, France) as well as to evaluate the outcome of the proximal humerus fracture treated with this implant. 8 patients with a mean age of 62.5 years were operated with immediate passive rehabilitation and active exercises initiated around day 45. All patients had good results with minimal pain, a mean Constant - Murley score of 74 and an acceptable shoulder amplitude. The clinical success was assured by the anatomic union of the tuberosities around the implant. The Arrow metaphyseal corundum blasted humeral titanium stem assures a perfect osseointegration with optimal stability and is an efficient alternative for shoulder hemiarthroplasty.
\end{abstract}

Keywords : unipolar shoulder prosthesis, proximal humerus fractures, corundum blasted humeral titanium stem, passive rehabilitation, shoulder hemiarthroplasty

Fractures of the proximal humerus in adults account for $4-5 \%$ of all fractures [1] and are the third most frequent fracture in the elderly following fractures of the proximal femur and distal radius [2,3].

While most simple fractures can be treated nonsurgicaly, prosthetic hemiarthroplasty has become an accepted method of treatment for some subgroups of proximal humerus fractures, including 4-parts fractures, 3-parts fractures in elderly patients with poor bone quality, fracture-dislocation, fractures of the anatomic neck (especially in old aged people) and fractures affecting the joint surface of the humeral head (of head splittype) which imply the destruction of over $50 \%$ of the humeral head $[4,5]$.

Four-parts fractures of the proximal humerus are difficult lesions and represent a challenge for the orthopaedic surgeon. Due to the vascularization impairment, both orthopaedic and surgical treatment lead to unfavourable results [6-9], and the only accepted attitude in the case of elderly patients is arthroplasty $[10,11]$. This type of surgery allows a good functional result for comminuted or irreparable articular fractures [12].

In young patients motivated for a thorough post-operative rehabilitation, hemiarthroplasty is an alternative solution to osteosynthesis, especially in the case of high-energy trauma, where the risk of osteonecrosis is increased [10, 13].

The hemiarthroplasty in proximal humeral fractures was sustained by Neer in the 1970s [6] who presented excellent results in around $90 \%$ of his patients. The next studies with this innovative technique reported results strongly related upon anatomic union of the tuberosities around the implant [14-16]. Despite the patient satisfaction after hemiarthroplasty with the pain - free shoulder, some restriction in active elevation [17-19], prompted the proposal of reversed total arthroplasty for the treatment of 3 -or 4 - parts fractures of the proximal humerus in elderly subject $[20,21]$.

\section{Experimental part}

The aim of this experimental study is to reveal the design and characteristics of unipolar shoulder prostheses type Arrow (Groupe $\mathrm{FH} \circledast$, France) as well as to analyze the outcome of the treatment of 8 patients with 3 - or 4 - parts proximal humeral fractures using this implant with an uncemented metaphyseal corundum blasted humeral titanium stem; the patients were operated at the Department of Orthopaedics and Traumatology of the Universitary Clinic Hospital Sf. Spiridon Iasi and at the Emergency County Hospital Piatra Neamt, between 2014 2016.

\section{Prosthetic design}

The Arrow platform system [22] asures for hemiarthroplasty a stem and a humeral head (fig. 1).

The titanium humeral stem (fig 1) is corundum blasted in the metaphyseal part (allowing bone ingrowth) and a smooth diaphyseal part (that can be cemented or uncemented). The shape of the humeral stem ensures a high stability of the prosthesis due to the good press fit metaphyseal fixation and preservation of the bone stock of the humerus; The lateral fin avoids stem rotation. The lenght of the stem between 120 and $170 \mathrm{~mm}$ prevents varus or valgus malposition.

The humeral head has an anatomic design and is made of cobalt chrome. The possibility of placing the head centered or off centered helps reproduce the anatomical medial and posterior offset of the humerus. The shape of

\footnotetext{
* email: carmen.cotruţ@gmail.com; Crististan0ogmail.com
} 
the head covers the stem plate leaving no space between the collar and the head, thus increasing the articular surface. The head comes in 6 sizes $(40,44,46,48,50$ and 54$)$ with a thickness between 12 and $18 \mathrm{~mm}$.

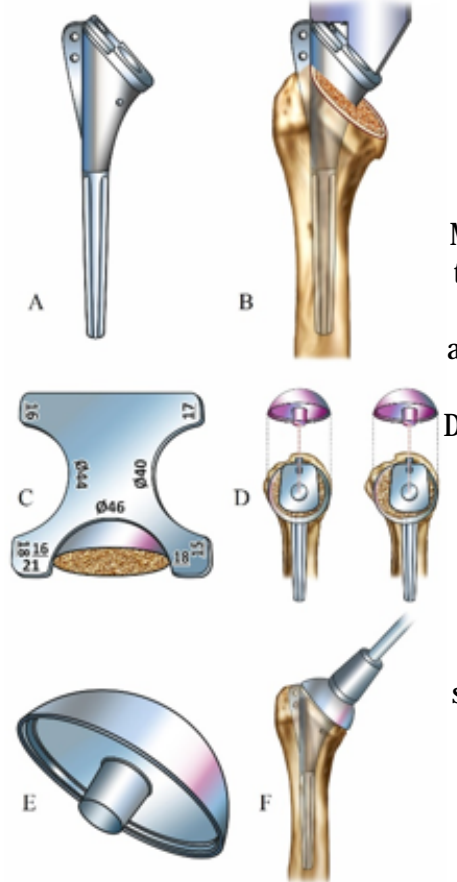

Fig. 1 (A-F) Arrow Platform System for unipolar hemiarthroplasties; (A-B) Metaphyseal corundum blasted titanium humeral stem; C -The diameter and thickness of the articular head is measured with the humeral head template;

-A centered or an off-centered trial humeral head is used in order to cover the bone as much as possible;

(E - F) - The definitive cobalt chrome humeral head is impacted onto the humeral stem. Adapted image from [22]

The study consisted of a retrospective analyses of 8 female patients with complex proximal humeral fractures ( 6 with 4 parts and 2 with 3 parts), with an average age of 62.5 years (range $56-76)$. The mean interval between the accident and the surgery was 14 days (range 5 - 28 days).

\section{Surgical technique}

All the patients were operated with general anesthesia, in a beach chair position and upper limb free, through a deltopectoral access, without or with minimal desinsertion of the deltoid ( fig. 2E). The deltoid and cephalic vein were retracted laterally and pectoral medially while not damaging the coracoacromial ligament. The axillary and the musculocutaneus nerves were protected. The bicipital groove was a critical landmark while the fracture line between the greater and lesser tuberosity is located posterior to the groove. In cases with 3 - parts fractures, the lesser tuberosity was osteotomized for creating a 4 parts fracture. After the sectioning of the tendon of the long head of the biceps (routinely tenodesis of the humeral insertion of the pectoralis major muscle), the humeral head is removed and the tuberosities are tagged with heavy sutures (fig. 2G - I, fig 3E - F) Next, the humeral channel is exposed and prepared with a sequential reaming until there was a sensation of reaming into the cortex (fig. 2J). Then the metaphysis is progressively prepared using increasing size of trial rasps; The retroversion of 20-30 degree of humeral component was realized using anatomical landmarks and by aligning the retroversion shaft attached to the metaphyseal rasp handle and the forearm (fig. $2 \mathrm{~K}$ $\mathrm{L}$, fig. 3G -H). After introduction of the last rasp and trial humeral head, reduction was realized verifying height and the stability of the prosthesis (fig. $2 \mathrm{M}-0$, fig. $3 \mathrm{l}-\mathrm{J}$ ); Temporary reduction of the tuberosity below the head of the modular prosthesis was realized with towel clips for verifying the position and acceptable adjustment to the stem collar (fig. 2P, fig. 3K). At the end we replaced the trial rasp with the definitive corundum blasted titanium humeral stem and the definitive centered or off-centered humeral head was impacted onto the stem (fig. $2 R-U$, fig. $3 L$ ). The final reduction of the prosthesis was realized (fig. 2V) and both tuberosities were fixed with 2 horizontal cerclage sutures followed by 2 vertical figure -in -eight sutures (fig. $2 \mathrm{~W}-\mathrm{X}$ ). A final check of the stability of the repair and range of motion was realized. Wound closure was realized with aspirative drain (fig. 2Y). Perioperative control radiographs were realized in order to confirm the position of the implants and of the tuberosities.

The patients shoulders were immobilized postoperative in an internal shoulder rotation orthesis with 30 degrees arm abduction for $30-45$ days.

Postoperative rehabilitation started after first week with pendular exercises and passive anterior flexion exercises. Active rehabilitation was started after the $6^{\text {th }}$ week while strengthening exercises only after 12 weeks. All pacients underwent clinical and radiographical examination with a mean follow-up of 14 months (range 12-20 months).

Despite numerous adapted shoulder scores [23], clinical assessment was performed using Constant - Murley score (which includes pain, mobility, activity and strength) [24] and active joint amplitudes in the operated shoulder. Radiological evaluation was conducted with special attention to the position of corundum blasted titanium stem (with osseointegration), as well as to the healing and position of the tuberosities.

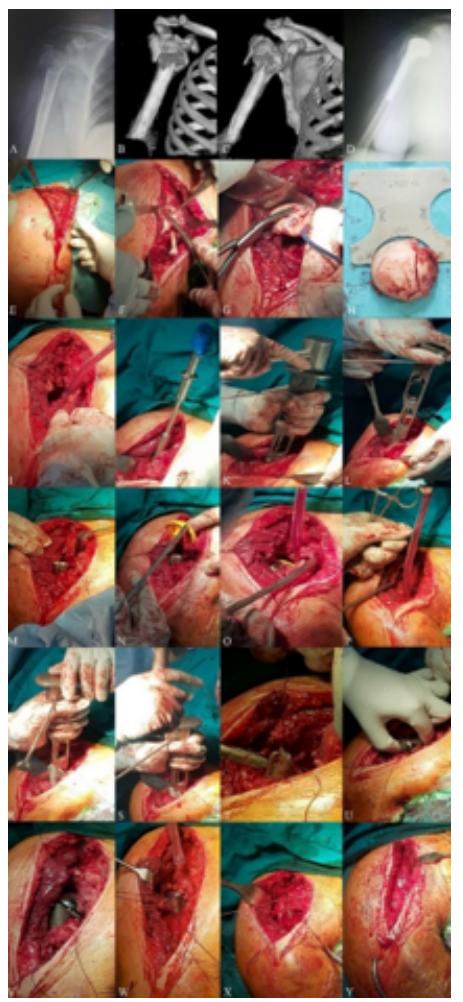

Fig. 2 (A -Y) - Hemiarthroplasty for a 3 - parts proximal humeral fracture using unipolar uncemented Arrow prosthesis (4 weeks after accident); A - Preoperative x-ray; (B-C) - CT images with 3D reconstruction; $D$ - Postoperative $x$-ray; $E$ - Deltopectoral approach; $\mathrm{F}$ - Sectioning of the tendon of the long head of the biceps; $\mathrm{G}$ Humeral head removal; $\mathrm{H}$ - Humeral head measurement with the humeral head template; I - The tuberosities are tagged with heavy sutures and retracted; I - Manually diaphyseal reaming with increasing size of reamers; $K, L$ - Manually preparation of the humeral metaphysis with increasing size rasps and reproducing the retroversion (20-30 degrees); M, N, 0 -Attaching the trial humeral head, performing the reduction and assess glenohumeral stability ; P -Temporary reduction of the tuberosities below the head of the modular prosthesis; R, S, T - Introducing the definitive humeral stem; $U$ - Impact the definitive humeral head onto the

humeral stem; $V$ - Reduction of the humeral prosthesis;

$W, X$ - Sutures of the tuberosities;

$$
Y \text { - Wound closure }
$$




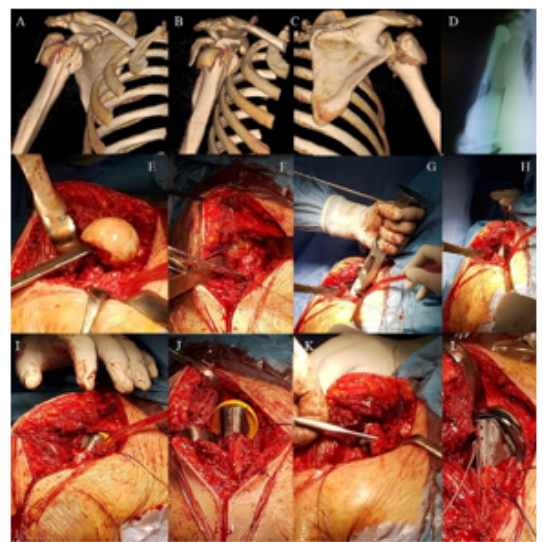

\section{Results and discussions}

While all our patients had minimal pain with improving everyday comfort, the mean Constant - Murley score was 74, (limits 34-92) (table 1). In evaluating the active range of motion at the final follow-up we found the following means : abduction $98^{\circ}$ (limits 40 - 140); anterior elevation $112^{\circ}$ (limits 60-150); external rotation with the elbow at the side $26^{\circ}$ (limits 0 -30) and internal rotation at 90 degrees abduction $51^{\circ}$ (limits 0 - 60).

\section{Table 1}

CLINICAL RESULTS AT THE FINAL FOLLOW-UP

\begin{tabular}{|c|c|c|}
\hline Results & Mean Value & Average \\
\hline $\begin{array}{c}\text { Constant - } \\
\text { Murley score }\end{array}$ & 74 & $34-92$ \\
\hline Abduction & 98 & $40-140$ \\
\hline Anterior elevation & 112 & $60-150$ \\
\hline $\begin{array}{c}\text { External rotation } \\
\text { with the elbow at } \\
\text { the side }\end{array}$ & 26 & $0-30$ \\
\hline $\begin{array}{c}\text { Intermal rotation } \\
\text { and 90 degrees } \\
\text { abduction }\end{array}$ & 51 & $0-60$ \\
\hline
\end{tabular}

From the radiographical evaluation we found abnormal tuberosity positioning and healing problems in 2 patients. Tuberosity healing was good in the other 6 patients while we found 3 cases with periprosthetic ectopic ossifications.

The osseointegration of the uncemented metaphyseal corundum blasted humeral titanium stem was optimal [25], with no partial or complete radiolucency around the humeral component. Two patients had significant limitations of movement that were treated conservatively with long-term rehabilitation. There were no infections or implant instability.

In case of 4-parts fractures of the proximal humerus, the results are influenced by many factors: age of the patient, quality of bone [26], the moment when the surgical intervention took place, deficiencies in the surgical technique, post-surgical complications, post-surgical rehabilitation $[5,27,28]$. A favorable and functional prognosis can be anticipated for a younger patient without pre-surgical neurological deficit or post-surgical complications and with a satisfactory aspect of the shoulder after 6 weeks. The results are weaker in the larger group of old-aged patients (often poorly motivated and suffering from other associated conditions), especially in those who show neurological deficit, a post-surgical complication which requires reintervention or an excentrically-placed prosthesis with retracted tuberosities $[5,27,29]$. As for the time of the surgical intervention, it has been noted that early prosthetic (less than 4 weeks after the trauma) leads to a better prognostic in terms of functionality $[28,30]$. As the lesion grows older, the recovery of function and mobility rate of the prosthetic shoulder become weaker [31]. Furthermore, the results can be influenced by the incomplete solving of the anatomical and surgical issues: damage in the circumflex nerve, early or secondary migration of the tuberosities as a consequence of a deficient reinsertion $[5,27,29]$. Despite the increase using of reverse shoulder arthroplasty [29] or introducing new type of shoulder prosthesis [32,33], displaced 3 -parts or 4 -parts proximal humeral fractures are best treated with hemiarthoplasty (especially in elderly). The crucial aspect is to understand the key concepts of well - performing this demanding operation.

\section{Conclusions}

Hemiarthroplasty for 3 or 4 parts proximal humerus fracture provides good results, a high subjective satisfaction rate with absence of pain and improving the patients everyday comfort. The challenge in this difficult surgery is correctly establishing the height and retroversion of the stem as well as the strong suture of the tuberosities which allow anatomic union around the implant. The uncemented metaphyseal corundum blasted titanium stem type Arrow assures a perfect osseointegration with optimal stability of the prosthesis.

\section{References}

1.LIND T, KRONER K, JENSEN J. The epidemiology of fractures of proximal humerus. Arch Orthop Trauma Surg.1989;108(5):285-7.

2.COURT-BROWN CM, CAESAR B. Epidemiology of adult fractures: 381, a review. Injury 2006;37:691-7.

3.ROBINSON PM, HARRISON T, COOK A, PARKER MJ. Orthopaedic injuries associated with hip fractures in those aged over 60 years: a study of patterns of injury and outcomes for 1971 patients. Injury 2012;43:1131-4.

4.MOECKEL BH, DINES DM, WARREN RF, ALTCHEK DW. Modular hemiarthroplasty for fractures of the proximal part of the humerus. J Bone and Joint Surg. 1992 J uly; 74(6):884-89

5.ROBINSON CM, PAGE RS, HILL RMF ET ALL. Primary Hemiarthroplasty for treatment of Proximal Humeral Fractures. J Bone and J oint Surg (Am).2003;85:1215-1223

6.NEER CS 2ND. Displaced proximal humeral fractures. II. Treatment of three part and four-part displacement. J Bone Joint Surg Am. 1970;52(6):1090-103.

7.HERTEL R, HEMPFING A, STIEHLER M, LEUNIG M. Predictors of humeral head ischemia after intracapsular fracture of the proximal humerus. J Shoulder Elbow Surg. 2004;13(4):427-33.

8.PETRIGLIANO FA, BEZRUKOV N, GAMRADT SC, SOOHOO NF. Factors predicting com-plication and reoperation rates following surgical fixation of proximal humeral fractures. J Bone Joint Surg Am 2014;96:1544-51.

9.NEUHAUS V, BOT AG, SWELLENGREBEL CH, JAIN NB, WARNER JJ, RING DC. Treatment choice affects inpatient adverse events and mortality in older aged inpatients with an isolated fracture of the proximal humerus. J Shoulder Elbow Surg2014;23:800-6.

10.COMPITO CA, SELF EB, BIGLIANI LU. Arthroplasty and acute shoulder trauma: reasons for success and failure. Clinical Orthopaedics \& Related Research. 1994 Oct; 307:27-36 
11.ANTUNA SA, SPERLING JW, COFIELD RH. Shoulder hemiarthroplasty for acute fractures of the proximal humerus: a minimum 5-year followup. J Shoulder Elbow Surg 2008;17:202-9.

12.SIRBU, PD, TUDOR, R, BEREA， G， SCRIPCARU， A, CIUBARA, B, BADULESCU, OV; Bipolar Polyethylene Radial Head Arthroplasty in Posttraumatic Unstable Elbows. Prosthetic design and clinical results, Mat. Plast., 54, no. 2, 2017, p. 298-301

13.BALLMER FT, HERTEL R. Indications and results of shoulder prosthetics in complex proximal humerus fractures. Ther Umsch. 1998 Mar; 55(3):197-202

14.MOVIN T, SJ ODEN GO, AHRENGART L. Poor function after shoulder replacement in fracture patients. A retrospective evaluation of 29 patients followed for 2-12 years. Acta Orthop Scand. 1998;69(4):392-6. 15.BOILEAU P, KRISHNAN SG, TINSI L, WALCH G, COSTE S, MOLÉ D. Tuberosity malposition and migration: reasons for poor outcomes after hemiarthroplasty for displaced fractures of the proximal humerus. J Shoulder Elbow Surg. 2002;11(5):401-12.

16.KONTAKIS G, KOUTRAS C, TOSOUNIDIS T, GIANNOUDIS P.

Early management of proximal humeral fractures with

hemiarthroplasty: a systematic review. J Bone Joint Surg Br. 2008;90(11):1407-13.

17.PRAKASH U, MCGURTY DW, DENT JA. Hemiarthroplasty for severe fractures of the proximal humerus. J Shoulder Elbow Surg. 2002;11(5):428-30.

18.KRAUSE FG, HUEBSCHLE L, HERTEL R. Reattachment of the tuberosities with cable wires and bone graft in hemiarthroplasties done for proximal humeral fractures with cable wire and bone graft: 58 patients with a 22-month minimum follow-up. J Orthop Trauma. 2007;21(10):682-6.

19.GRONHAGEN CM, ABBASZADEGAN H, REVAY SA, ADOLPHSON PY. Medium-term results after primary hemiarthroplasty for comminute proximal humerus fractures: a study of 46 patients followed up for an average of 4.4 years. J Shoulder Elbow Surg. 2007;16(6):766-73.

20.SIRVEAUX F, FAVARD L, OUDET D, HUQUET D, WALCH G, MOLÉ D. Grammont inverted total shoulder arthroplasty in the treatment of glenohumeral osteoarthritis with massive rupture of the cuff. Results of a multicentre study of 80 shoulders.J Bone J oint Surg Br 2004;86:38895.

21.CAZENEUVE JF, CRISTOFARI DJ . GRAMMONT reversed prosthesis for acute complex fracture of the proximal humerus in an elderly population with 5 to 12 years follow-up. Orthop Traumatology Surg Res 2014;100:93-7.

22.*** http://ww w.fhortho.com/products/shoulder/arrow/ 23.HARAGUS, H., PREJBEANU, R., PATRASCU, J., FAUR, C., ROMAN, M., MELINTE, R., MARRA, G. (2018). Cross-cultural adaptation and validation of the Romanian Oxford Shoulder Score. Medicine, 97(23), e10926. https://doi.org/10.1097/MD.0000000000010926
24.CONSTANT CR, MURLEY AH. A clinical method of functional assessment of the shoulder. Clin Orthop 1987;214:160-4.

25.SIRBU PD, T PETREUS, FL. MUNTEANU, M. PERTEA, S. LUNCA, V. POROCH, P. BOTEZ, Clinical Experience with a Macroporous Synthetic Bone Substituite (Eurocer) in the Treatment of the Patients with Bone Defects. International Conference on Advancements of Medicine and Health Care through Technology IFMBE Proceedings, 2011, Volume 36. Part 5, 358-368, DOI: 10.1007/978-3-642-22586-4_75

26.SIRBU, PD,TUDOR, R., VERINGA, V, CIUNTŪ, B. M., RADU, V. , CIUBARA, B., BADULESCU, O. V. , Strontium Ranelate in the Healing of Fractures Complicated with Delayed Union. It is really effective?, Re. Chim. (Bucharest), 68, no. 8, 2017, p. 2537-5733

27.BOILEAU P, CALIGARIS-CORDERO B, PAYEUR F, TINSI L, ARGENSON $C$. Prognostic factors during rehabilitation after shoulder prostheses for fracture. Rev Chir Orthop Reparatrice Appar Mot. 1999 May; 85(2):106-16

28.LAUCHLAN C., JOSHUA S. D., DEAN G., LORICH, DAVID M. D. Hemiarthroplasty for proximal humerus fractures. Shoulder (JSDINES, SECTION EDITOR), Curr Rev Musculoskeletal Med. (2013), 6:57-62, DOI 10.1007/s12178-012-9152-9

29.BONNEVIALLE N. , TOURNIER C. , CLAVERT P. , OHL X. , SIRVEAUX F., SARAGAGLIA D. Hemiarthroplasty versus reverse shoulder arthroplasty in 4-part displaced fractures of the proximal humerus: Multicenter retrospective study. Orthopaedics \& Traumatology: Surgery \& Research, Elsevier Volume 102, Issue 5, September 2016, Pages 569-573

30.BOSCH U, FREMEREY RW, SKUTEK M, LOBENHOFFER P, TSCHERNE $\mathrm{H}$. Hemiarthroplasty -primary or secondary measure for 3- and 4fragment fractures of proximal humerus in the elderly?. Unfallchirurg. 1996 Sep; 99(9): 656-64

31.DIMAKOPOULOS P, POTAMITIS N, LAMBIRIS E. Hemiarthroplasty in the treatment of the comminuted intraarticular fractures of the proximal humerus. Clinical Orthopaedics \& Related Research. 1997 Aug; 341:7-11

32.TOMOAIA G, BENEA H, MICLEA L. Computed study of shoulder dynamics. Kinematics and dynamic analysis of shoulder movement. Automation, Quality and Testing, Robotics, AQTR 2008. IEEE International Conference, Cluj-Napoca, Romania, May 22-25. 3:90-93. E-ISBN:978-1-4244-2577-8. Print ISBN:978-1-4244-2576-1. 2008. IEEE.DOI 10.1109/AQTR.2008.4588889

33.HERLE S, MARCU C, BENEA H, MICLEA L, ROBOTIN R. SimulationBased Stress Analysis for a 3D Modeled Humerus-Prosthesis Assembly. Conference: International Joint Conferences on Computer, Information, and Systems Sciences, and Engineering (CISSE) Location: Bridgeport, CT Date: DEC 04-12, 2009. Sponsor(s): Inst Elect \& Elect Engineers; Univ Bridgeport. INNOVATIONS IN COMPUTING SCIENCES AND SOFTWARE ENGINEERING Pages: 343-348 Published: 2010

Manuscript received: 5.09 .2018 